\title{
Infrastructure Vandalism and Protection in a Vulnerable Zimbabwean Environment: Review of the Structural Materialism Theory
}

\author{
Chingozha Misheck P, Zvokuomba Kwashirai
}

\begin{abstract}
Many institutions are facing or have faced challenges related to vandalism of equipment and property in Zimbabwe. This criminal phenomenon is not only restricted and peculiar to this country but is experienced in other regions of the world, however with variations. The purpose of the study is to explore and unpack the various dimensions of infrastructure vandalism by gazing at Zimbabwe Electricity Supply Authority (ZESA) a power utility in Zimbabwe. The level of vandalism has been increasing unabated resulting in in a multitude of undesirable effects on the power utility and the economy as a whole. A plethora of stimulants have been seen to be triggering and sustaining the theft and vandalism of the infrastructure which targets copper conductors, copper windings, oils and the poles in the majority of cases. The study adopted the mixed method approach due to its technical advantage of converging and merging qualitative and quantitative data in order to provide comprehensive results and produce new knowledge claims. This methodological framework was guided by the structural materialism theory which is an off shot of the critical criminology perspective. Thus, the study found out that infrastructure vandalism is representative of a broader dysfunctional socioeconomic system of a country riddled by poverty, unemployment and the absence of mores and values within communities. Consequently, the levels of infrastructure vandalism have spiraled to unprecedented levels. The study concludes that the government is failing to sufficiently address the macro-economic fundamentals as way of discouraging citizens from engaging in crime and criminality while the traditional leaders are not being respected yet they have a significant role they can play in promoting the stability and serenity of communities. In view of these conclusions the study recommends that all stakeholders contribute towards the protection of all infrastructure and migrate to digitalize the protection of such infrastructure as well as promulgation of appropriate pieces of legislation.
\end{abstract}

Keywords: vandalism, infrastructure, criminology, vulnerability, protection.

\section{INTRODUCTION}

\section{A. GENERAL BACKGROUND TO THE STUDY}

There is a rise of damage to public property and vandalism of infrastructure of some utility companies that are inclusive of Zimbabwe Electricity Supply Authority (ZESA), Telone and National Railways of Zimbabwe (Commissioner (2019).

Manuscript received on August 03, 2021.

Revised Manuscript received on August 17, 2021.

Manuscript published on September 30, 2021.

* Correspondence Author

Misheck Chingozha, Lecturer, Zimbabwe Open University Faculty of Applied Social Sciences \& Faculty of Commerce and Law, Zimbabwe University of Johannesburg, Zimbabwe.

(C) The Authors. Published by Blue Eyes Intelligence Engineering and Sciences Publication (BEIESP). This is an open access article under the CC BY-NC-ND license (http://creativecommons.org/licenses/by-nc-nd/4.0/)
Kwashirai Zvokuomba, Research Associate, Department of sociology,

Consequently, so much revenue is lost as business is brought to a halt by the effects of theft and vandalism. The cost of repairs has been painstakingly too high which Tsokota, Chipfumbu, Mativenga and Mawango (2013) puts at US\$100million (The Standard (2020), the effect of which has been to deny the ordinary citizens access to basic utilities. Damage to infrastructure has a serious offsetting effect on productivity and sustainable livelihoods to which Monica Mutsvangwa the Minister for the Information, Publicity and Broadcasting Services has called for stringent measures to curb 'the upsurge in cases of vandalism and theft of cables resulting in destruction of infrastructure at Zesa, Telone and National Railways of Zimbabwe.' ZBC/TV (2020). According to The Herald (2020) the 'surge in transformer thefts was alarming'. The same article (ibid) also went on to say, "patients could not get their meals on schedule as the hospital resorted to coal to cook. The renal or kidney unit had to be closed temporarily, threatening the lives of the patients. Most departments had to be switched to diesel powered generators to ensure they stayed open for at least emergency cases'. Thus the purpose of the study is to explore and unpack criminal matrix around public property vandalism and proffer possible protection measures. The first part of the research article focuses on the general background to the study which highlights the main research question, the theoretical, conceptual and methodological framings. The second part gazes at the presentation and discussion of findings.

A lot of lives have been lost as a result of the damage of the infrastructure. Examples include those that die from electrocution as a result of contact with broken live electricity wires, those that fail to call for assistance because of vandalised telecommunications wires in the event of accident, robberies or violence against their persons, those that die in health facilities when transformers are vandalised and many similar instances. In the majority of cases, these lives would not have been lost (Chingozha, 2018) which is testimony to the fact that vandalism creates an unsafe environment for the communities. What this development appears to confirm could be the reality that there is something not right between the relationship of the police and the public as the equipment so vandalised gets a ready market with no one motivated to report to the police hence the compelling need to digitalize infrastructure protection. Historically communities had respect for each other and authority but the moral fibre has weakened while moral decadence is now rife.

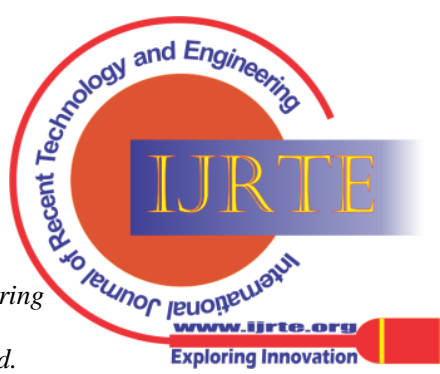


The extent of infrastructure vandalism in Zimbabwe is so apparent and has seriously impacted the economy. Many institutions have been affected to the extent that they had to incur a lot of costs in repairing or replacing the damaged equipment or cables. Some industries have faced vandalism induced blackouts. The effects of infrastructure vandalism are apparent within the country as revealed by the study. Various sectors of the economy have had to face the ugly realities of such vandalism that include but not limited to interrupted service at hospitals and other institutions, disrupted rail service, interrupted ICT facilities, deaths due to electrocution and so forth. The study revealed that millions of dollars in revenue and repairs have been lost due to theft and vandalism of the utility infrastructure yet the focus within the utilities is to maximise shareholder wealth, improve electrification for the nation through national grid expansion, improving connectivity through rail network and improving customer reputation. ZESA for example lost about USD\$728 722.52 between January and September 2020, Telone has been losing US\$600 000 annually for the past five years while the NRZ (Eastern area) witnessed a record of 189 cases between 2015 and 2019 in which several thousands of value was lost to vandals (Moyo 2018). These findings aptly confirm the findings of Tsokota et al. (2013) who carried a similar study in one of ZESA'S sub-units. Moyo (2018) shown that vandalism and theft of public infrastructure has caused government departments and municipalities to lose property and equipment worth more than US\$100 million every year and shared Dansi et al (2019) sentiments in a paper themed, 'Cable Theft and Vandalism by Employees of South Africa's Electricity Utility Companies: A Theoretical Exploration and Research Agenda' found out that in terms of socio-economic impact. According to Solomon (2013) cable theft and vandalism has interrupted the schedules of Gautrain, Johannesburg's electric powered inter -city railway transport system. This has resulted in persistent delays due to signaling problems, interferences of telephone networks and several accidents at faulty robots leading to traffic jams. Cable thefts have also been held responsible for the numerous deaths due to electric engineers repairing and maintaining vandalised substations and copper cables (Peters, 2014). Cable theft and vandalism has affected many utilities to the extent that utilities such as Eskom and Transnet have declared a loss of up to R1.2 billion between 2006 and 2012 (Michael, 2012) This is quite a massive loss that has serious financial implications on institutions. These figures also agree with what has happened at Telkom, a South African Telecommunications Company, which indicated that the entity lost R1.9 million in repairs and replacement cost between 2006-2011 (Michael, 2014) while Namibian Telecom Report (2012) suggests that Namibian Telecoms suffered losses amounting to N\$760 000 in 2012 due to theft and vandalism of copper cables. Thus the study sought to answer the research questions; what is the nature of public infrastructure vandalism? What is the motivation and how can such property be protected?

\section{THEORETICAL AND CONCEPTUAL FRAMING}

Vandalism and protection of infrastructure at the Zimbabwe Electricity Supply Authority (ZESA) in this study is explained and understood from the structural materialism theory of crime which has its origins from critical criminologists (Merth 2016). The theory asserts that, '...crime is a making of society and that people tend to take to crime primarily as a result of existential conditions' (Alemika (2013:56). Therefore it implies that the structural materialism of crime is based on the perceptive that the structure matters, hence, the structural foundations of society establish both the character and undercurrents of society. Thus in the case of ZESA infrastructure in Zimbabwe, the vandalism is fundamentally and structurally both in essence and in origin. Alemika (ibid) further argues that the dynamics that are to blame for the vandalism are embedded in the socio-structural foundations of society particularly the material state of affairs of the people, the state and the economy at large. Thus, according to Okoli (2016), the theory seeks to answer the questions; what are the socioeconomic imperatives in that society where vandalism takes place? What is the prevalence of corruption and unemployment? Thus theoretically, when vandalism starts at the top political and bureaucratic through spillage of public resources, it spills to lower levels and the scenario creates a vicious cycle of criminality. Therefore, the theory gives a guide in understanding and interpreting aspects of vandalism of a public utility organization as it engages digitalization as a broad strategy of crime prevention

Conceptually, vandalism is understood from a classical definition by Ward (1973) which posits that it is the willful damage to property through specific behaviors which is the opposite of damage through decay, erosion or other physical changes through the subjection to natural environment. The same conceptual framing is given by Wilson (1961) who considers vandalism as a result of willful or thoughtless behaviour towards the build up environment. Thus vandalism of ZESA infrastructure is understood from the vantage point of these classical theorists and critical criminological framing.

\section{RESEARCH METHODOLOGY}

The mixed method approach according to Creswell (2009:18) be one in which the study tend to support knowledge claims on pragmatic foundation, that is, the problem centred perspective. It employs strategies of examination that involve gathering empirical data that make the research problem understandable. Thus in this case the study aim was not only to establish new knowledge claims but subsequently solve the problem of property vandalism and enhance its protection. The field work involved collecting data that was both numeric and textual such that the final product represented equally quantitative and qualitative information. Based on this pragmatic knowledge claim strategy and philosophy, the field realities assumed that collecting diverse data sets provided a deeper understanding of the problem of vandalism as the research participants were from the security sector. They were drawn from the loss control departments and sections of ZESA and from the officers from the Zimbabwe Republic Police using a nonprobability sampling technique.

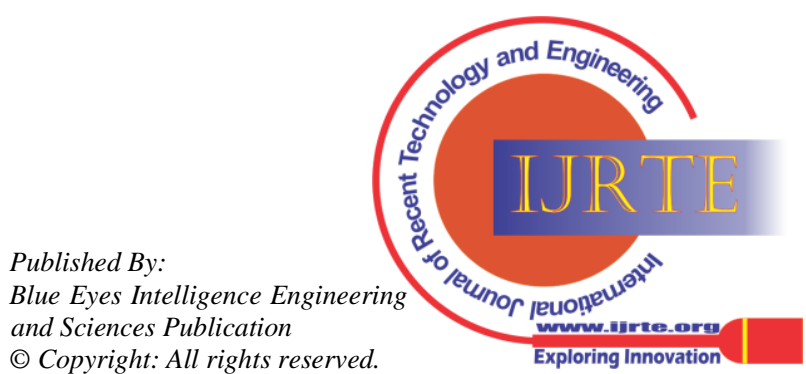


The data collection started with the deployment of a structured questionnaire to 100 participants in order to create generalizable results, then in the second phase, the in-depth interview guide was utilised to collect qualitative data, compounded by a documentary analysis. In that way the study generated both generalised findings about the problem and detailed views of the concept of vandalism.

\section{FINDINGS}

\section{Vandalism; an inside job}

The study established amazing findings in that criminals vandalize infrastructure and at times high voltage cables and equipment, for example, the 11 and 33 kilovolts transmission conductors, get away with transformer coils, transformer oil. The study established that this is not an easy task for ordinary persons who may not have knowledge of electrical generation, transmission or distribution.

Ordinarily those who work on and with such high voltages ought to possess a respectable level of competencies to be able to deal with such high levels of voltages and specialized equipment like transformers. Without these competencies, the individuals would put their lives in danger. The study established that in terms of the Institute of Electrical Engineers regulations, those without the requisite skills are not allowed to work on or with such high voltages. One of the Loss Control Officers (LCO 1) said,

at times the manner in which the thefts are conducted is just smart, which is an indication that this cannot be the work of mere criminals but individuals with competencies in electrical engineering. The perpetrators should surely be electricians or engineers within or outside ZESA because there are times when as ZESA we employ contract workers. At the expiry of their contracts these workers go with their knowledge of the system and could be the ones who because of the high levels of unemployment or mere mischief return to steal from the former employer

This empirical evidence point to the fact that vandalism of ZESA infrastructure in the form of theft of cables and other appliances is partly done by employees of the organization or former employees. This position was almost an open secret with other members of staff but the problem lied with a weak property protection system. This was also corroborated by the address by the Head of State (Zimbabwe) who stressed that Zesa employees were involved in the destruction of the infrastructure. He went further to warn them to desist from this practice which is said to be causing a lot of hemorrhage on the economy. In the address cited by The Herald (October, 19 2019) he said, "...Zesa workers have a hand in the rampant vandalism and theft of electricity infrastructure which has cost the country millions of dollars and led to disruptions of efficient power transmission across the country." In this regard, the study refuted Mazikana's (2019) proposition that vandalism and theft of infrastructure was perpetuated by unemployed people in the community. The extent to which some operations fail clearly shows that information would have been leaked from within. The Head of State went further to say, "...We are convinced that those who steal transformers either work for Zesa or are related to Zesa workers because you need some degree of information and technology to steal these transformers and you must know that there is some danger involved." In an interview with one of the police officers the research learnt that there was a time when it was discovered that an employee deployed in the control room (at Telone) in which alarms that protect various networks would be monitored was actually a part to the syndicate. Instead of advising the security when alarms had been triggered, the employee would conceal the information so that the perpetrators execute their operation without any hindrance. This practice was said to be prevalent in virtual all such utilities. One such employee was however discovered but after the organization had lost significantly in terms of replacement cost of infrastructure, customer confidence and revenue in flows. The losses was as high as over R5billion (about half a billion US dollars) a year in revenue losses (Hi Tec Solutions, South Africa. Some respondents from the Prison revealed that the main copper dealers incentivize the officers who then find it very difficult to resist the offers extended to them for various roles that would aid the theft and vandalism of infrastructure. This was confirmed by the CENTLEC Case Management Report, 2012; CENTLEC Financial and Asset Loss Report, 2012 (South Africa) which found out investigations into infrastructure vandalism and theft in some jurisdictions has led to a discovery of the involvement of the company employees. This is very unfortunate because ideally company employees should jealously guard the resources for their company so that they will have guaranteed employment into the future (Densai et al., 2014). Ordinary unemployed youth may not have the required skills and knowledge to engage in such dangerous activities. The study argue that is the unemployed person become part of the vandalism and criminality, they would be only be providing assistance to those with specialized skills. Therefore, in this section we argue that vandalism and theft of ZESA property is perpetuated by those with required skills and knowledge of ZESA operations, hence, it is part of the 'inside job'. Those from within the organization had their 'hands' on these criminal as evidenced by the report from the security division of the organization.

\section{Infrastructure vandalism matrix in Zimbabwe.}

The study established the various aspects related to infrastructure vandalism in Zimbabwe and came up with an infrastructure vandalism matrix in Zimbabwe. The analysis of the responses generated in this study helped develop the infrastructure vandalism matrix represented by figure 1 . These aspects as shown by this matrix include,

The causes of the theft and vandalism: the causes of theft and vandalism of infrastructure according to this study included incentive pricing of copper conductors, poor investigations of cases under the Copper Act, weak pieces of legislation regulating the trade in copper, lucrative market within the country and outside and the need to survive by the perpetrators

The items, components or equipment vandalized: The study revealed that the vandals target various components on the network that include cables, pylons, transformers, transformer windings and oil and poles.

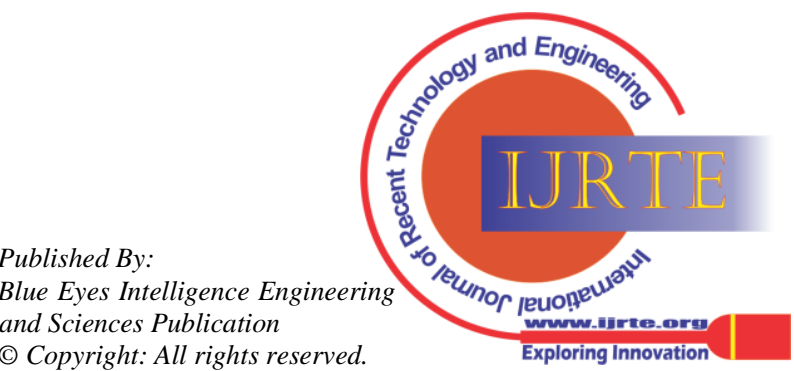


What needs to be done to curtail vandalism, benefits of a sound infrastructure: In response to what needs to be done to curtail such theft and vandalism the respondents suggested improved laws, whistle blowing, combined operations between Zesa security, the national police, other utilities like Telone and the National Railways of Zimbabwe, ensuring that the workforce is sufficiently motivated so that they are not tempted to engage in crime as well as passing deterrent sentences to those arrested.

Who to blame for theft and vandalism of infrastructure and effects of infrastructure vandalism: The study also identified what can be blamed for theft and vandalism of infrastructure vandalism. The respondents revealed that a bad economy, the existing legislation, corrupt employees and incompetent internal security can be blamed for the theft and vandalism of infrastructure at Zesa.

The effects of theft and vandalism of infrastructure: The study revealed that the effects of theft and vandalism of infrastructure include loss of connectivity, interrupted services, deaths, revenue loss and cost of repairs

Benefits of sound infrastructure: The study also revealed the benefits of a sound infrastructure imploring the adoption of digitalization of infrastructure protection. The benefit include investor confidence, customer satisfaction, improved connectivity and improved national grid

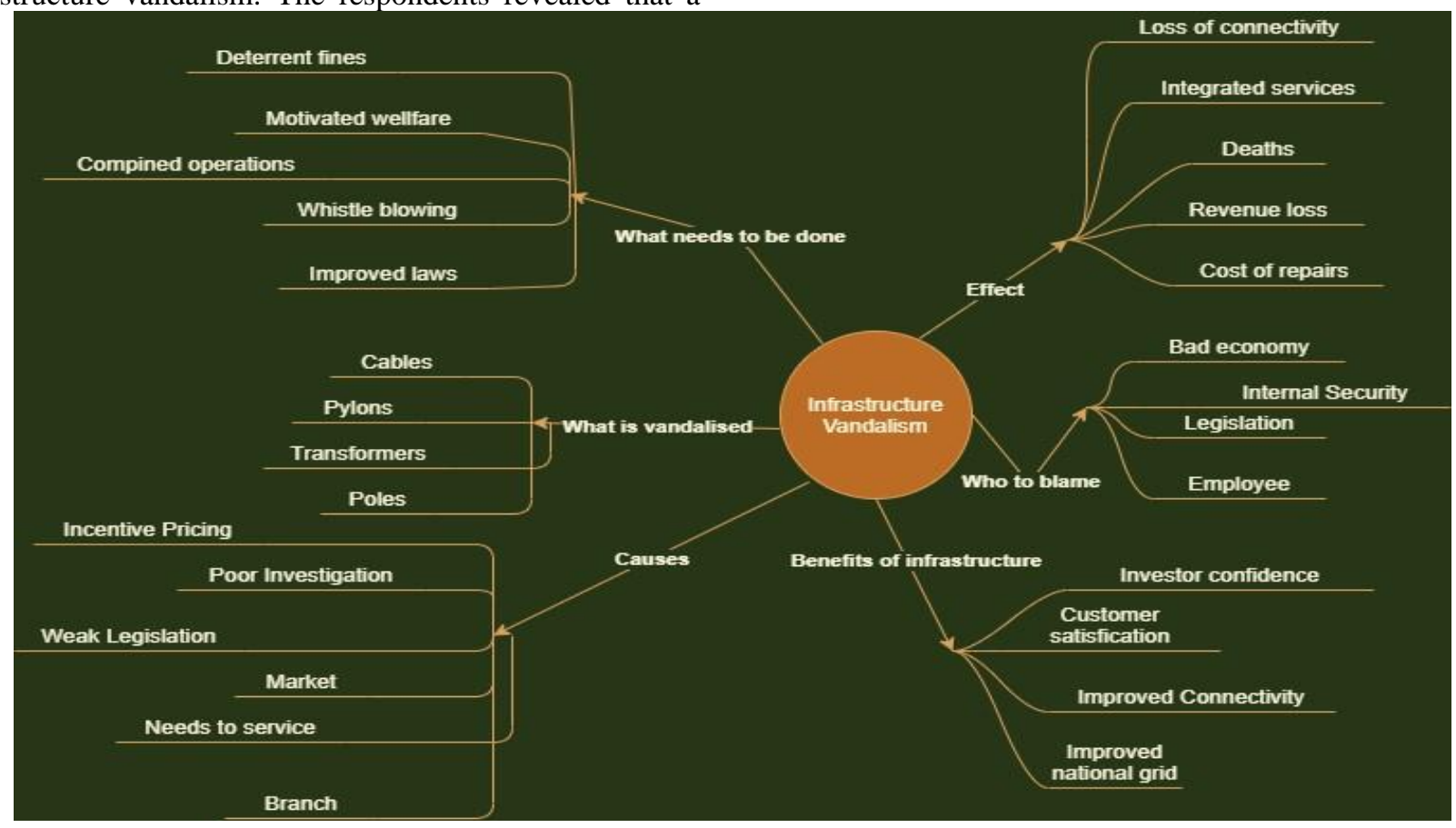

Fig 1. Infrastructure vandalism matrix: Source, Chingozha 2021.

The study revealed that the preservation of networks and infrastructure is not the responsibility of the police alone but all citizens. In this vein those interviewed from ZESA indicated that the company was on a drive to conscientise citizens that the infrastructure that ZESA manages was public property through the mantra, '...It's not Zesa property but our property.' The import of this mantra is that all citizens have a role to play in safeguarding the infrastructure. When the infrastructure is vandalized the citizens are the losers and this is what needs to be understood by all and sundry. In this regard it was the considered view of virtually all the respondents that the various stakeholders and communities have an obligation to ensure the security of the infrastructure. This finding agrees with Tsokota et al. (2013) who also found out that, "everyone ought to take part in protection of sovereignty and property, which contributes greatly to the expansion and stabilization of the economy.' The matrix above clearly shows the various issues raised by the various respondents regarding the centrality of a sound infrastructure in the growth and survival of an economy. In the absence of the commitment by the citizens to join hands and deal with theft and vandalism of infrastructure the study revealed the only other way would be to digitalize the protection of such infrastructure for tec.

According to the study infrastructure vandalism represent a level of vulnerability within the socioeconomic and political system. When a people are faced with hunger and survivalist

Retrieval Number: 100.1/ijrte.C63550910321

DOI: 10.35940/ijrte.C6355.0910321

Journal Website: www.ijrte.org issues, they do not apportion value on public infrastructure. They would pounce on it for survival instead yet the involvement of citizens in safeguarding the infrastructure would result in target hardening (ability to make it difficult for criminals to commit crime) because of their visibility and attitude towards ownership of the infrastructure. The study also revealed that the participation of citizens in the protection of infrastructure had proved to work within the low density areas when compared with the high density areas. This was however confirmed as being insufficient since people by their nature are not consistent and reliable compared to technology. In view of this thinking, a respondent from Harare Central Prison serving a 10-year mandatory sentence indicated that he was actually arrested by the local residents as he tried to bring down the copper that was hanging loose within the Borrowdale area in Harare. However, Ikejemba and Schuur (2017) asserted that as long as there are government inequalities within a polity, citizens would continue to engage in infrastructure vandalism and theft for the purpose of economic survival. Adding his voice to this thinking the Public Relations Officer for ZESA said

Published By:

Blue Eyes Intelligence Engineering and Sciences Publication

13 (C) Copyright: All rights reserved.

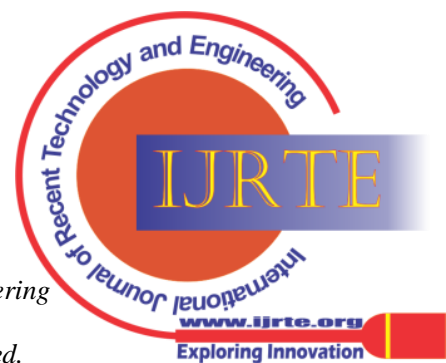


replacing vandalized equipment requires all stakeholders affected...we need to address the issue of theft and vandalism before we replace the equipment because once someone is used to vandalism then they would do the same to the newly installed wires...(Field interview 27/9/2018) officers from ZESA southern region. They all concurred that the national infrastructure can only be secure when all citizens work together and share the national vision that deplores crime and criminality complimented by digitalizing the protection mechanisms for the circuits and networks. These respondents stated that bad relations disrupt or prohibit flow of information from the communities yet information is paramount for the survival of every institution. The respondents also revealed that criminals are not terrestrial monsters but reside within the communities which confirms individuals who commit crimes within communities are known by someone within that community. This position demonstrated that communities are undisputedly consumers of the proceeds of crime while some communities are victims of the vandalised infrastructure.

This agrees with the findings of a study by Ikejemba and Schuur (2017) who found out that people tend to put across their frustration by vandalising infrastructures and engage in illegitimate activities that may well provide them with income to survive daily. Technology would however help to these perpetrators at bay. As the people share a common vision, they will safeguard their infrastructure consistent with the result of a study by Tsokota et al. who establish that dealing with the vandalism scourge requires a multifaceted approach that is complimented by appropriate technologies.

\section{Vulnerable economy and Corruption}

The study established through the security division of ZESA that they were 27 cases of corruption that originated from cases of vandalism to ZESA property particularly copper cables in 2018. Due to the severity of the cases, attempts to engage in corruption through bribing a police officer or a judiciary officer occurred. These reported cases represented just a small fraction of the whole matter as many other officials would just accept the bribe and get away with it. An interview with the prison officer also indicated that one out of five of the imprisoned criminals who committed vandalism crimes acknowledge that they did it out of poverty and the need to survive. The economic status of Zimbabwe currently act as a stimulant to the commission of some economic crimes. The study, further argues that property vandalism and theft at ZESA represent a wider socioeconomic and political decay which is a reality of life. Communities create some form of sub-culture which originates from some form of vulnerability, poverty and lack. The study shares this thinking with critical criminologists Cozen et al (2005) and Carrington et al 2016 who further argue that corruption at a higher level in the bureaucratic systems of organisations act as enabler of economic and organized crimes. A sentiment shared by the Chief Security Officer for ZESA was that infrastructure vandalism was about criminal livelihoods and implored the government to work on the economic fundamentals so that the socio economic situation improves. This view was confirmed by Ikejemba and Schuur (2017) who said, 'the incompetence and failure of government to generate jobs, social security and other essential necessities arouses the antagonism within the people and as such lead to the vandalization of
The same thinking was advanced by the loss control

infrastructure'. The majority of these respondents went on to suggest that engaging in crime and criminality was motivated by the status of the economy, level of corruption and the absences of mores among citizens. Thus in the case of ZESA infrastructure vandalism is fundamentally and structurally both in essence and in origin out of poverty and the need to survive and as argued by Alemika (2013) that the factors that are to blame for the vandalism are entrenched in the sociostructural fundamentals of society particularly the material circumstances of the people, the state and the economy at large. This position equally dovetails into the infrastructure vandalism matrix as presented in Figure 1.

In another interview with respondent LCO 04 the study noted that the manner the offence is committed at times is reflective of the possibility of inside information having been passed to the perpetrators. Respondent LCO 04 said, 'ordinarily there is no way an ordinary citizen would know the exact location of a cable that is buried underground. At times, some of the cables are buried at a depth of 3 to 5 meters and protected by alarms but what becomes disturbing is how the perpetrators know that the alarm is down and then pounce. This surely is reflective of inside involvement.'

The study discovered that there are so many copper cables lying idle from non-operational networks or circuitry. The theft of these cables is very difficult to determine unlike the operating networks which immediately impact on customers when service is discontinued. The majority of those serving at Harare Prison indicated that they were victims of picking up cables that were

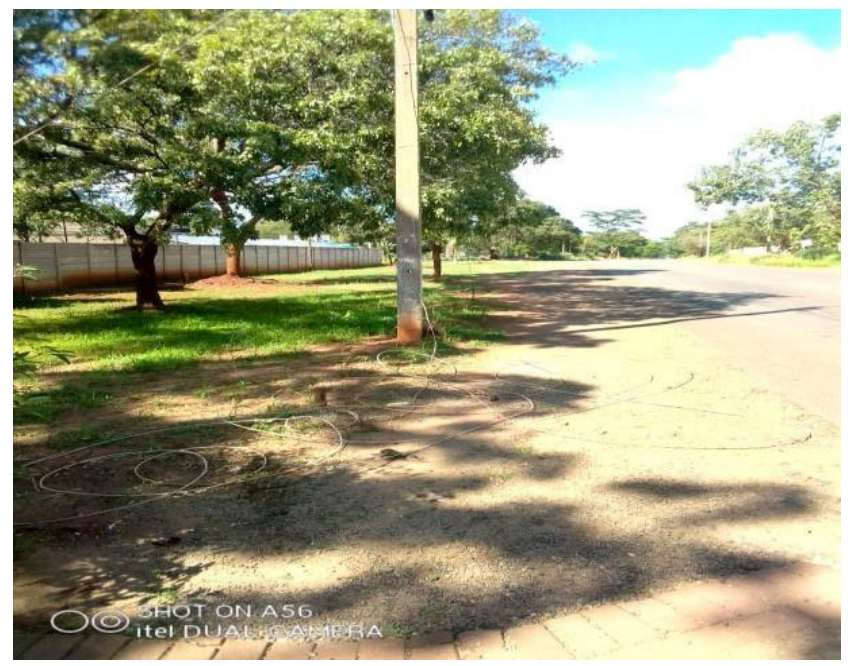

Fig 2 Unrecovered copper cables

hanging loose. They totally denied vandalising the infrastructure blaming it on the authorities that failed to recover their cables or repair their circuits. This response was further collaborated by community leaders interviewed at the ZESA residential Complex in Harare who then directed this researcher to the electricity distribution line next to their office (see in the insert below showing a loosely hanging copper conductor). Some respondents from TM PICK AND PAY supermarkets (Harare) also who directed this researcher to an unrecovered copper conductor along Rhodesville avenue (Fig 2).

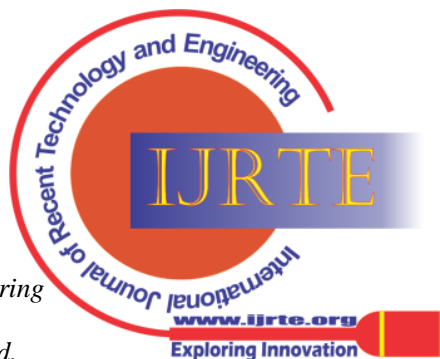


There was convergence of thought that the authorities at ZESA and indeed many other utilities should have mechanisms that promote prompt response to recover loosely hanging copper conductors to prevent criminals from preying upon them.

\section{CONCLUSIONS}

The study brought to the fore a number of issues related to property vandalism at ZESA including organized crime from 'within', corruption, the social and economic environment as enablers of crime and criminality. Handling of property or equipment related to electricity generation, transmission and distribution requires a modicum of expertise. Consequently, the study maintained the argument that vandalization of electricity infrastructure equipment and installations could only be done by those with specialized skills and know how. The study thus concludes that the government is not addressing the macroeconomic fundamentals which is resulting in the high level of unemployment while traditional leaders are not being respected as an important contributor towards a crime free community which inevitably leads to moral decadence. The study equally concludes that trading in copper or copper products is not being closely monitored and regulated leading to leakages and a lot of illegal dealings since offenders under the Copper Act are not being appropriately punished.

\section{RECOMMENDATIONS}

In view of the conclusions drawn in this study it is recommended that public utilities should adopt appropriate technologies to protect their infrastructure, restrict the engagement of casual and contract workers so as to safeguard installations. Where these are engaged they must be vetted thoroughly by the internal security and the National police with the unparalleled view to isolate any likelihood of engaging individuals with a questionable record. The police and the people should work together so that they manage to handle crime and criminality, build trust and confidence and promote legitimacy within their communities through creating more channels of communication to facilitate the flow of information from communities through inspiring confidence and trust within the communities. It is also recommended that, the police to adopt smart policing creativities. Smart policing is a recent thinking which emphasise the effective use of data and analytics which are now a must for focused policing institutions. Such an intervention equally improves the analysis, execution and assessment research that promotes efficiency and encouraging innovation). This reduces direct interaction between police and public hence reduce or eliminate unnecessary clashes. Smart policing in other words refers to the use of appropriate technologies that monitor the police officers as they discharge their duties as well as monitoring the activities of citizens as they go about their business. They will be in a position to see a crime being committed from a control room because of the cameras deployed at various sites. All stakeholders, as government, business, private citizens, traditional leader or watchdogs should work together with the police in the fight against crime as the police institute programmes that promote social cohesion and sustainable livelihoods for citizens and institutions. The stakeholders include the judiciary officers who must pass deterrent sentences on those convicted, the policymakers who must harmonize all pieces of legislation related to copper trading; the business who must also avail resources to the police so that the police are not overwhelmed, the traditional chiefs who must enforce their values, government who must constantly revisit available pieces of legislation, revoke copper licenses from non- institutional holders, resources to the police as well as addressing the macroeconomic fundamentals.

\section{CONCLUSION}

The arguments and recommendations advanced by this paper were premised on the data that was generated by this research. The findings indicated that theft and vandalism of infrastructure at Zesa is on the increase and that the involvement of employees this utility could not be overruled in view of how the cases were committed in the majority of the times. More importantly the study revealed that the macro-economic fundamentals and breakdown societal mores were the major contributors to the vandalism scourge.

\section{REFERENCES}

1. Akers, R. 1966. A Differential Association: Reinforcement Theory of Criminal Behaviour. Social problems, Vol 14 No 2

2. Akers, R. 2002. A Social Learning Theory of Crime. Criminological Theories: Bridging the Past to the Future, sage

3. Bowen, G. 2009. Document Analysis as Qualitative Research Method. Qualitative Research Journal, Vol 9 Issue 2

4. Bruhn, A. 2009. The concept of Social Cohesion in the Group Effect. Boston, Springer

5. Bryman, A. 2012. Mixed Methods: Combining qualitative and quantitative research. Social Research Methods, pages 727-651

6. Carrington, K. Hogg, R. and Sozzo, M. 2016. Southern Criminology. British Journal of Criminology. 56. 1-20.

7. Chingozha M.P and Mawere, M. 2015. Negotiating Law, Policing and Morality in Zimbabwe, Langaa Publishers, Cameroon

8. Chingozha, M. 2019. Policing; Can Society Dispense With It? Bulawayo: TEPP Marketing.

9. Chingozha. 2018. Client charter. (Interview in the Outpost Police Magazine)

10. Clarke, V.N. 2021. To saturate or not to saturate? Questioning data saturation as a useful concept for thematic analysis and sample size rationales, Qualitative Research in Sport, Exercise and Health Vol 13(2) 201-216

11. Cozens, P. Savilie, G and Hillier, D. 2005. Crime Prevention through Environmental Design. A Review and Modern Bibliography. Property Management 23. 328-356.

12. Dlamini, S. 2010. Theft of Copper Wire, Mbabane, Royal Eswatini Police Newsletter

13. Editor, T. H. 2020. Theft of Copper Cable on the Increase. Harare: The Herald.

14. Editor. 2014. Theft of Copper wires. Mbabane: Royal Eswatini Newsletter.

15. Editor. 2014. Theft of Copper wires. Mbabane: Royal Eswatini Newsletter.

16. Editor. 2020. Crime. Harare: The Herald.

17. Editor. 2020. Crime. Harare: The Herald.

18. Editor. 2020. Theft of Copper Cables. Harare: The Herald.

19. Editor. 2020. Theft of Copper Cables. Harare: The Herald.

20. Herald, 2019. ED takes ZESA to task over vandalism

21. Herald, 2020. Infrastructure vandalism

22. Ikejemba, E. and Schuur, P. 2017. Analyzing the impact of theft and vandalism in relation to the sustainability of renewable energy projects in Sub Saharan Africa

23. Jackson, J. 2009. Why do people comply with the law? Legitimacy and the influence of legal institutions. The British Journal of Criminology, Vol 52 issue 6

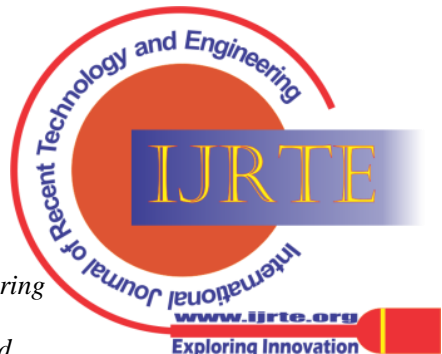


24. Moyo, A. 2018. ZETDC fights infrastructure vandalism, The Herald

25. Newsletter, R. E. 2010. Infrastructure Vandalism. Mbabane: Royal Eswatini Police Newsletter.

26. Police, R. E. 2013. The Newsletter. Mbabane: Royal Eswatini Police.

27. Police, R. E. 2019. Newsletter. Mbabane: Royal Eswatini Police.

28. Solomon. R. 2013. Vandalism of Infrastructure. Mbabane: Royal Eswatini Police Newsletter.

29. Tsokota, T, Chipfumbu, C.T, Mativenga, M \& Mawango. T.I. 2013. The challenges of infrastructure vandalism in Zimbabwe

30. Ward, C. 1973. Vandalism. The Architectural Press, London. 23-53.

31. Wilson, G. T. 1961. Vandalism-How to stop it. American Institute of Park Executive Management aids. Bullet 7.

32. Zimbabwe Broadcast Corporation ZBC/TV. 2020.

\section{AUTHORS PROFILE}

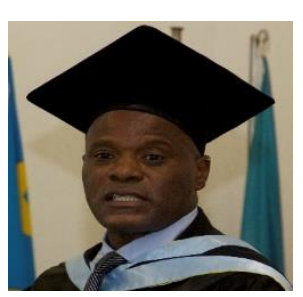

Misheck Chingozha, is a doctoral student with Chinhoyi University of Technology (Zimbabwe) and holds a masters in business administration (MBA), masters in peace leadership and conflict resolution (MSPL) and masters in development studies (MDS). He is currently the interim principal to the SARPCCO Centre of Excellence (a training academy for SADC) and lecturer for Zimbabwe Open University (Faculty of Applied Social Sciences \& Faculty of Commerce and Law) and Police Staff College (associate college of University of Zimbabwe). His research interests are in security and development issues, gender, peace and leadership. Email chingozhamp@gmail.com

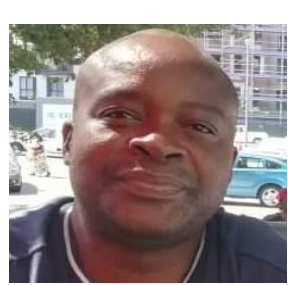

Kwashirai Zvokuomba, is a research associate in the department of sociology at the University of Johannesburg and holds a PhD from the same institute. $\mathrm{He}$ is a senior researcher in the department of development studies at the Zimbabwe Ezekiel Guti University and his research interests cut across issues of gender and development, land and agrarian studies, cultural and sociology of crime studies. Email zvokuombak@gmail.com orcid 0000-0002-8152-9621

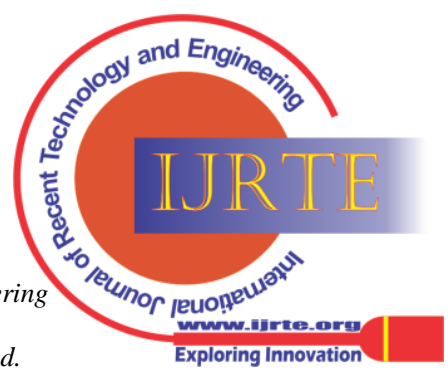

